\title{
ANALISIS KECELAKAAN KERJA PADA PEKERJA PENGELASAN DI CV. CAHAYA TIGA PUTRI
}

\section{Analysis of Work Accidents in Welding Workers in CV. CAHAYA TIGA PUTRI}

\author{
Dwi Marina Rizka Pisceliya ${ }^{1}$, Sri Mindayani ${ }^{2}$ \\ ${ }^{1,2}$ Dosen Tetap Fakultas Kesehatan Masyarakat - Universitas Baiturrahmah, Padang \\ Email : dmrpisceliya@gmail.com, sri.mindayani@gmail.com
}

\begin{abstract}
Abstrak
Kecelakaan kerja adalah efek samping yang tidak diinginkan terhadap manusia, merusak properti atau merugikan proses. Data dari ILO pada 2013 mengatakan bahwa satu pekerja meninggal setiap 15 detik karena kecelakaan di tempat kerja. Penelitian ini bertujuan untuk menganalisis kecelakaan pada pekerja las di CV. Cahaya Tiga Putri Kelurahan Sungai Sapih Kecamatan Kuranji Padang pada tahun 2017. Desain penelitian yang digunakan adalah studi cross-sectional. Penelitian ini dilakukan di CV. Cahaya Tiga Putri Padang terletak di Jalan Lolongkaran Sungai Sapih Padang pada bulan Desember hingga Juli 2017. Populasi dalam penelitian ini adalah pekerja las. Sampel diambil menggunakan teknik total sampling, sebanyak 32 orang. Data dianalisis univariat dan bivariat dengan uji chi-square. Hasil penelitian menunjukkan bahwa 46,9\% responden mengalami kecelakaan kerja, 53,1\% responden memiliki perilaku tidak aman, 53,1\% responden tidak aman, 56,3\% responden memiliki pengetahuan buruk. Dari hasil uji statistik diketahui ada hubungan antara tindakan tidak aman dengan kecelakaan kerja, ada hubungan antara kondisi tidak aman dengan kecelakaan kerja dan ada hubungan antara pengetahuan dengan kecelakaan. Untuk mengurangi jumlah kecelakaan kerja, diharapkan bahwa pekerja harus selalu bekerja dengan menggunakan alat pelindung diri (APD), menciptakan lingkungan kerja yang aman dan bagi pemilik untuk meningkatkan pengetahuan pekerja dengan memberikan pelatihan dan promosi kesehatan kerja dan keselamatan kerja. seperti konseling tentang APD.
\end{abstract}

Kata kunci: Kecelakaan Kerja, Tindakan Tidak Aman, Kondisi Tidak Aman, Pengetahuan

\begin{abstract}
A work accident is an undesirable adverse event against a human, damaging property or disadvantage to the process. Data from the ILO in 2013 says that one worker die every 15 seconds due to workplace accidents. This study aims to analyze accidents in welding workers in CV. Cahaya Tiga Putri Kelurahan Sungai Sapih Kecamatan Kuranji Padang in 2017. The research design used was crosssectional study. This research was conducted at CV. Cahaya Tiga Putri Padang located at Jalan Lolongkaran Sungai Sapih Padang in December to July 2017. The population of this research were welding workers. Samples were taken using total sampling technique, as many as 32 people. Data were analyzed univariat and bivariate with chi-square test. The result of the research shows that $46,9 \%$ of respondents have work accident, $53,1 \%$ of respondents have unsafe behavior, $53,1 \%$ of respondent have unsafe condition, 56,3\% respondent have bad knowledge. From the statistical test results known there was a relationship between unsafe acts with work accidents, there was a relationship between unsafe conditions with work accidents and there was a relationship between knowledge with accidents. To reduce the number of occupational accidents, it is expected that workers should always working with using personal protective equipment (PPE), create a safe working environment and for the owner in order to improve worker knowledge by providing training and promotion of occupational health and safetty such as counseling about PPE.
\end{abstract}

Key words : Work Accident, Unsafe Action, Unsafe Condition, Knowledge

\section{PENDAHULUAN}

Kesehatan dan keselamatan kerja merupakan salah satu aspek perlindungan tenaga kerja yang bertujuan agar tenaga kerja dapat melaksanakan pekerjaan dengan nyaman, sehat dan aman, sehingga tercapai peningkatan produktifitas kerja secara optimal. Oleh karena itu tenaga kerja harus memperoleh perlindungan dari berbagai masalah di tempat kerja yang dapat menimbulkan penyakit akibat keja dan kecelakaan kerja (Silaban, 2014).

Undang-undang nomor 1 Tahun 1970 menjelaskan bahwa setiap tenaga kerja berhak mendapatkan perlindungan atas keselamatan dalam melakukan pekerjaan untuk kesejahteraan dan 
meningkatkan produktivitas nasional serta terjaminnya keselamatan.

Kecelakaan kerja adalah suatu kejadian atau peristiwa yang tidak diinginkan yang merugikan terhadap manusia, merusak harta benda atau kerugian terhadap proses. Kecelakaan kerja juga dapat didefinisikan suatu kejadian yang tidak dikehendaki dan tidak diduga semula yang dapat menimbulkan korban manusia dan atau harta benda (Suma'mur, 2009).

Berdasarkan data International Labour Organization (ILO) tahun 2013, 1 pekerja di dunia meninggal setiap 15 detik karena kecelakaan kerja dan 160 pekerja mengalami sakit akibat kerja. Pada tahun 2012, ILO mencatat angka kematian dikarenakan kecelakaan dan penyakit akibat kerja (PAK) sebanyak 2 juta kasus setiap tahun.

Menurut Badan Penyelenggara Jaminan Sosial (BPJS) Ketenagakerjaan, di Indonesia hingga akhir 2015 telah terjadi kecelakaan kerja sebanyak 105.182 kasus. Sementara itu, untuk kasus kecelakaan berat yang mengakibatkan kematian tercatat sebanyak 2.375 kasus dari total jumlah kecelakaan kerja.

Penelitian yang dilakukan Waruwu (2015) di Yogyakarta penyebab kecelakaan kerja di bengkel pengecatan mobil dimana di peroleh dari kondisi tidak aman 18 orang $(36,4 \%)$ di antaranya pernah mengalami kecelakaan kerja, sedangkan tindakan tidak aman yang mengalami kecelakaan kerja sebanyak 16 orang $(30,1 \%)$.

Setiap kejadian kecelakaan kerja pasti akan menimbulkan dampak maupun kerugian baik bagi tenaga kerja (termasuk rekan kerja, keluarga), pemilik perusahaan/industri maupun masyarakat (masyarakat sekitar industri dan konsumen). Adapun kerugian-kerugian yang disebabkan kecelakaan akibat kerja kerja yaitu: kerusakan (damage), kekacauan organisasi (disorganization), keluhan dan kesedihan (distress), kelainan dan cacat (disability), dan kematian (death) (Silaban, 2014).

Menurut Heinrich dalam Silaban (2014) secara umum penyebab langsung kecelakaan kerja terbagi atas dua golongan, yaitu unsafe action (faktor manusia) dan unsafe condition (faktor lingkungan). Unsafe action dapat disebabkan oleh faktor manusia itu sendiri seperti: ketidakseimbangan fisik tenaga kerja, kurang pendidikan, bekerja melebihi jam kerja, menjalankan pekerjaan tidak sesuai keahliannya dan mengangkut beban yang berlebihan, sedangkan kecelakaan yang disebabkan oleh keadaan yang tidak aman (unsafe condition) disebabkan karena tempat kerja yang tidak sesuai dengan aturan kesehatan dan keselamatan kerja yang telah ditentukan. Dari hasil-hasil penelitian bahwa 80-85\% kecelakaan disebabkan oleh kelalaian atupun kesalahan manusia.

Karateristik penyebab umum kecelakaan antara lain adalah karena faktor perilaku pekerja itu sendiri yaitu kurangnya pengetahuan pekerja tentang pentingnya Alat Pelindung Diri (APD), sikap pekerja sudah merasa profesional sehingga penggunaan APD tidak diperlukan lagi pada saat bekerja.

Masalah kecelakaan kerja banyak terjadi di berbagai industri, salah satunya pengelasan. Pengelasan merupakan suatu kegiatan penting pada proses fabrikasi baja untuk menyatukan dua buah baja sesuai dengan susunan dan rancangan yang telah ditetapkan. Pengelasan atau welding adalah penyambungan dua bahan atau lebih yang didasarkan pada prinsip-prinsip proses difusi, sehingga terjadi penyatuan bagian bahan yang disambung (Riswan, 2008 dalam Wicaksono 2014).

Penelitian Safirin (2007) dalam Wicaksono (2014) menyebutkan bahwa kasus kecelakaan kerja yang terjadi pada bagian welder adalah luka bakar di bagian tangan dan muka pada saat melakukan pengelasan.

Penelitian yang dilakukan Aswar, dkk (2016) pada pekerja bengkel mobil 
menyatakan bahwa ada hubungan antara pengetahuan K3 dengan kecelakaan kerja. Dimana responden dengan pengetahuan K3 cukup sebagian besar mengalami kecelakaan ringan 14 orang $(28,6 \%)$. Sedangkan responden yang dengan pengetahuan K3 kurang sebagian besar responden mengalami kecelakaan berat 14 orang $(28,6 \%)$ dan sebagian kecil mengalami kecelakaan ringan 3 orang $(6,1 \%)$.

CV. Cahaya Tiga Putri merupakan unit usaha informal yang bekerja di bidang pengelasan. CV. Cahaya Tiga Putri ini memiliki 32 pekerja dimana pekerja yang berasal dari CV ini berjumlah 26 orang dan 6 orang lagi berasal dari 2 buah bengkel yang bekerja sama dengan CV. Cahaya Tiga Putri. CV. Cahaya Tiga Putri memiliki 2 buah bengkel dimana bengkel 1 memiliki luas $172 \mathrm{~m}^{2}$ dan luas bengkel 2 $1000 \mathrm{~m}^{2}$. Pekerjaan yang dilakukan dalam bidang pengelasan tersebut seperti pembuatan teralis, canopy, pagar, konsen hingga aksesoris bangunan. Jenis pengelasan yang digunakan yaitu las listrik, las stainless/argon dan las CO2.

Berdasarkan survei awal, dari 6 pekerja pengelasan yang diwawancarai di CV. Cahaya Tiga Putri ternyata 6 orang pekerja ini mengalami kecelakaan kerja pada saat bekerja yaitu 1 orang terjatuh, 1 orang terkena percikan gerinda yang masuk ke mata, 2 orang terluka karena gerinda dan 2 orang mengalami luka bakar. Kecelakaan yang terjadi karena pekerja melakukan pekerjaan secara tidak aman seperti pekerja tidak menggunakan APD saat bekerja, bekerja sambil merokok. Hal ini juga didukung oleh kondisi tidak aman yang ada di bengkel seperti tersandung karena permukaan lantai yang tidak rata, kabel yang berserakan, tidak adanya penyediaan APAR di bengkel serta kurangnya pengetahuan $\mathrm{K} 3$ pekerja seperti adanya pekerja yang tidak mengetahui apa itu APD hal ini disebabkan karena latar belakang pendidikan pekerja yaitu 1 orang yang tamatan S1 dan yang lainnya sebatas tamatan SMA dan SMK bahkan ada yang lulusan SMP. Sedangkan di bengkel tersebut sudah menyediakan APD yang lengkap untuk para pekerja tetapi masih sering ditemukan pekerja yang tidak menggunakan APD tersebut saat bekerja.

Berdasarkan latar belakang di atas, peneliti tertarik untuk melakukan penelitian tentang analisis kecelakaan kerja pada pekerja pengelasan di CV. Cahaya Tiga Putri.

\section{METODE PENELITIAN}

Jenis penelitian ini adalah survei analitik dengan pendekatan desain Cross Sectional Study. Penelitian ini dilakukan di CV. Cahaya Tiga Putri Kelurahan Sungai Sapih Kecamatan Kuranji Padang. Waktu penelitian dilakukan pada bulan Desember 2016 sampai Juli 2017. Populasi dalam penelitian ini adalah seluruh pekerja pengelasan di CV. Cahaya Tiga Putri Kelurahan Sungai Sapih Kecamatan Kuranji Padang. Sampel dalam penelitian ini adalah 32 pekerja.

Data primer dapat dikumpulkan melalui wawancara menggunakan kuesioner dan observasi untuk melihat tindakan tidak aman, kondisi tidak aman, pengetahuan dan kecelakaan kerja pada pekerja pengelasan. Data sekunder dapat diperoleh dari pimpinan CV. Cahaya Tiga Putri Kelurahan Sungai Sapih Kecamatan Kuranji Padang.

\section{HASIL PENELITIAN}

\section{Univariat}

Tabel 1. Distribusi Frekuensi Kecelakaan Kerja di CV. Cahaya Tiga Putri

\begin{tabular}{llcc}
\hline No & Kecelakaan Kerja & $\boldsymbol{F}$ & $\mathbf{\%}$ \\
\hline 1. & Pernah & 15 & 46,9 \\
2. & Tidak Pernah & 17 & 53,1 \\
\hline & Jumlah & 32 & 100 \\
\hline & Berdasarkan tabel & 1. & dapat
\end{tabular}
diketahui bahwa kurang dari separuh $(46,9 \%)$ responden pernah mengalami kecelakaan kerja. 
Tabel 2. Distrbusi Frekuensi Tindakan Tidak Aman di CV. Cahaya Tiga Putri

\begin{tabular}{llcc}
\hline No & $\begin{array}{l}\text { Tindakan Tidak } \\
\text { Aman }\end{array}$ & $\boldsymbol{f}$ & $\mathbf{\%}$ \\
\hline 1. & Aman & 15 & 46,9 \\
2. & Tidak Aman & 17 & 53,1 \\
\hline & Jumlah & 32 & 100 \\
\hline
\end{tabular}

Berdasarkan tabel 2. dapat diketahui bahwa lebih dari separuh $(53,1 \%)$ responden memiliki tindakan tidak aman.

Tabel 3. Distrbusi Frekuensi Kondisi Tidak Aman di CV. Cahaya Tiga Putri

\begin{tabular}{llcc}
\hline No & $\begin{array}{l}\text { Kondisi Tidak } \\
\text { Aman }\end{array}$ & $\boldsymbol{f}$ & $\mathbf{\%}$ \\
\hline 1. & Aman & 15 & 46,9 \\
2. & Tidak Aman & 17 & 53,1
\end{tabular}

\begin{tabular}{lll}
\hline Jumlah & 32 & 100 \\
\hline
\end{tabular}

Berdasarkan tabel 3. dapat diketahui bahwa lebih dari separuh $(53,1 \%)$ responden memiliki kondisi tidak aman.

Tabel 4. Distrbusi Frekuensi

Pengetahuan di CV. Cahaya Tiga Putri

\begin{tabular}{llll}
\hline No & Pengetahuan & $\boldsymbol{f}$ & $\mathbf{\%}$ \\
\hline 1. & Kurang Baik & 18 & 56,3 \\
2. & Baik & 14 & 43,8 \\
\hline & Jumlah & 32 & 100 \\
\hline
\end{tabular}

Berdasarkan tabel 4. dapat diketahui bahwa lebih dari separuh $(56,3 \%)$ responden memiliki pengetahuan yang kurang baik.

\section{Bivariat}

Tabel 5. Hubungan Tindakan Tidak Aman dengan Kecelakaan Kerja di CV. Cahaya Tiga Putri

\begin{tabular}{|c|c|c|c|c|c|c|c|}
\hline \multirow{3}{*}{$\begin{array}{c}\text { Tindakan Tidak } \\
\text { Aman }\end{array}$} & \multicolumn{4}{|c|}{ Kecelakaan Kerja } & \multirow{2}{*}{\multicolumn{2}{|c|}{ Jumlah }} & \multirow{3}{*}{$\begin{array}{c}\text { Nilai } p \\
\text { value }\end{array}$} \\
\hline & \multicolumn{2}{|c|}{ Pernah } & \multicolumn{2}{|c|}{ Tidak Pernah } & & & \\
\hline & $f$ & $\%$ & $f$ & $\%$ & $f$ & $\%$ & \\
\hline Tidak Aman & 13 & 76,5 & 4 & 23,5 & 17 & 100 & \\
\hline Aman & 2 & 13,3 & 13 & 86,7 & 15 & 100 & 0,001 \\
\hline Jumlah & 15 & 46,9 & 17 & 53,1 & 32 & 100 & \\
\hline
\end{tabular}

Berdasarkan tabel 5. dapat diketahui bahwa responden yang memiliki tindakan tidak aman lebih banyak mengalami kecelakaan kerja $(76,5 \%)$ dibandingkan dengan responden yang memiliki tindakan aman $(13,3 \%)$.
Berdasarkan hasil uji statistik diperoleh nilai $p$ value $=0,001$ berarti terdapat hubungan yang bermakna antara tindakan tidak aman dengan kecelakaan kerja.

Tabel 6. Hubungan Kondisi Tidak Aman dengan Keceakaan Kerja di CV. Cahaya Tiga Putri

\begin{tabular}{|c|c|c|c|c|c|c|c|}
\hline \multirow{3}{*}{$\begin{array}{c}\text { Kondisi Tidak } \\
\text { Aman }\end{array}$} & \multicolumn{4}{|c|}{ Kecelakaan Kerja } & \multicolumn{2}{|c|}{ Jumlah } & \multirow{3}{*}{$\begin{array}{l}\text { Nilai p } \\
\text { Value }\end{array}$} \\
\hline & \multicolumn{2}{|c|}{ Pernah } & \multicolumn{2}{|c|}{ Tidak Pernah } & \multirow[b]{2}{*}{$\boldsymbol{F}$} & \multirow[b]{2}{*}{$\%$} & \\
\hline & $f$ & $\%$ & $F$ & $\%$ & & & \\
\hline Tidak Aman & 13 & 76,5 & 4 & 23,5 & 17 & 100 & 0,001 \\
\hline Aman & 2 & 13,3 & 13 & 86,7 & 15 & 100 & \\
\hline Jumlah & 15 & 46,9 & 17 & 53,1 & 32 & 100 & \\
\hline \begin{tabular}{cc}
\multicolumn{2}{c}{ Berdasarkar } \\
iketahui $\quad$ bahwa
\end{tabular} & $\begin{array}{l}\text { tab } \\
\text { resp }\end{array}$ & $\begin{array}{l}6 . \\
\text { en }\end{array}$ & & $\begin{array}{l}\text { memi } \\
\text { banys }\end{array}$ & me & $\mathrm{imi}^{\mathrm{ti}}$ & tan \\
\hline
\end{tabular}


$(76,5 \%)$ dibandingkan dengan responden yang memiliki kondisi aman $(13,3 \%)$. Berdasarkan hasil uji statistik diperoleh nilai $p$ value $=0,001$ berarti terdapat hubungan yang bermakna antara kondisi tidak aman dengan kecelakaan kerja.

\section{Tabel 7. Hubungan Pengetahuan dengan Keceakaan Kerja di CV. Cahaya Tiga Putri}

\begin{tabular}{llccccccc}
\hline \multicolumn{1}{c}{ Pengetahuan } & \multicolumn{4}{c}{ Kecelakaan Kerja } & & Jumlah & \multicolumn{2}{c}{ Nilai p } \\
& \multicolumn{2}{c}{ Pernah } & \multicolumn{2}{c}{ Tidak Pernah } & & & value \\
& \multicolumn{1}{c}{$\boldsymbol{f}$} & $\boldsymbol{\%}$ & $\boldsymbol{f}$ & $\boldsymbol{\%}$ & $\boldsymbol{f}$ & $\boldsymbol{\%}$ & \\
\hline Kurang Baik & 13 & 72,2 & 5 & 27,8 & 18 & 100 & 0,004 \\
Baik & 2 & 14,3 & 12 & 85,7 & 14 & 100 & \\
\hline Jumlah & 15 & 46,5 & 17 & 53,1 & 32 & 100 & \\
\hline
\end{tabular}

Berdasarkan tabel 7. dapat diketahui bahwa responden yang memiliki pengetahuan kurang baik lebih banyak mengalami kecelakaan kerja $(72,2 \%)$ dibandingkan dengan responden yang memiliki pengetahuan baik (14,3\%). Berdasarkan hasil uji statistik diperoleh nilai $p$ value $=0,004$ berarti terdapat hubungan yang bermakna antara pengetahuan dengan kecelakaan kerja.

\section{PEMBAHASAN}

\section{Analisis Univariat}

\section{Kecelakaan Kerja}

Hasil penelitian dapat dilihat bahwa kurang dari separuh $(46,9 \%)$ responden pernah mengalami kecelakaan kerja. Hal ini dapat dilihat dari hasil penelitian sebanyak $100 \%$ pekerja terkena percikan api las, 75\% mengalami luka bakar, $65,6 \%$ pernah terkena percikan api gerinda yang masuk ke mata, $62,5 \%$ pernah terluka saat menggerinda.

Penelitian Safirin (2007) dalam Wicaksono (2014) menyebutkan bahwa kasus kecelakaan kerja yang terjadi pada bagian welder adalah luka bakar di bagian tangan dan muka pada saat melakukan pengelasan.
Kecelakaan kerja adalah suatu kejadian atau peristiwa yang tidak diinginkan yang merugikan terhadap manusia, merusak harta benda atau kerugian terhadap proses. Kecelakaan kerja juga dapat didefinisikan suatu kejadian yang tidak dikehendaki dan tidak diduga semula yang dapat menimbulkan korban manusia dan atau harta benda (Suma'mur, 2009).

Berdasarkan hasil penelitian di lapangan menunjukkan bahwa terjadi beberapa kecelakaan kerja, seperti responden terkena percikan api las, mengalami luka bakar, terkena percikan api gerinda yang masuk ke mata, dan pernah terluka saat menggerinda. Kecelakaan kerja yang terjadi dalam penelitian ini dapat disebabkan oleh pekerja tidak memakai baju kerja yang disediakan oleh pemilik bengkel, tidak berhati-hati saat bekerja karena pekerja bekerja sambil merokok dan bercanda saat mengelas, tidak menggunakan kacamata pada saat menggerinda sehingga percikan api gerinda tersebut bisa masuk ke mata, tidak menggunakan sarung tangan pada saat bekerja. Setelah diwawancarai, alasan responden tidak menggunakan sarung tangan karena jika memakai sarung tangan pada saat menggerinda akan terasa licin, memegang gerinda jadi tidak kuat sehingga tidak nyaman pada saat melakukan pekerjaan penggerindaan. 


\section{Tindakan Tidak Aman}

Hasil penelitian menunjukkan bahwa lebih dari separuh $(53,1 \%)$ responden memiliki tindakan tidak aman. Hal ini dapat dilihat dari hasil penelitian sebanyak $100 \%$ responden tidak memakai sarung tangan, safety shoes dan apron saat bekerja, 78,1\% tidak selalu hati-dalam bekerja, $65,5 \%$ responden bekerja sambil merokok.

Menurut Ilyas (2000) dalam Pratiwi (2009) perilaku tidak aman adalah perilaku yang dilakukan oleh pekerja yang menyimpang dari prinsip-prinsip keselamatan atau tidak sesuai dengan prosedur kerja yang berisiko untuk timbulnya masalah.

Menurut Kletz (2001) dalam Pratiwi (2009) menyatakan bahwa pada dasarnya tindakan/perilaku tidak aman merupakan kesalahan manusia dalam mengambil sikap/tindakan.

Tindakan tidak aman pada penelitian ini dapat dilihat dari hasil penelitian dimana pekerja tidak menggunakan APD seperti safety shoes, apron dan sarung tangan, bercanda sambil mengelas, merokok sambil bekerja dan pekerja juga sering tidak menggunakan kacamata saat mengelas dan menggerinda besi. Setelah diwawancarai, alasan responden melakukan tindakan tidak aman tersebut adalah memakai safety shoes saat bekerja itu terlalu berat dan tidak nyaman, ada juga yang mengatakan tidak terbiasa, tidak terbiasa memakai apron, memakai sarung tangan pada saat menggerinda maka akan terasa licin, pegangan pada gerinda menjadi tidak kuat sehingga menjadi tidak nyaman. Pekerja tidak hatihati pada saat bekerja karena ada pekerja yang merokok sambil bekerja dan bercanda sambil mengelas. Alasan pekerja merokok sambil bekerja karena menghilangkan bosan saat bekerja. Diharapkan kepada pekerja agar selalu memakai APD pada saat bekerja serta tidak merokok pada saat bekerja dan tidak bercanda pada saat sedang melakukan pekerjaan.

\section{Kondisi Tidak Aman}

Hasil penelitian menunjukkan
bahwa lebih dari separuh $(53,1 \%)$ responden memiliki kondisi tidak aman. Hal ini dapat dilihat dari hasil penelitian sebanyak 100\% lingkungan di tempat kerja terlalu bising, kabel-kabel berserakan di tempat kerja, tidak adanya APAR di tempat kerja dan alat yang digunakan beresiko kontak dengan listrik, 87,5\% adanya lantai berlubang di tempat kerja.

Penelitian yang dilakukan Waruwu (2015) di Yogyakarta penyebab kecelakaan kerja di bengkel pengecatan mobil dimana di peroleh dari kondisi tidak aman 18 orang $(36,4 \%)$ di antaranya pernah mengalami kecelakaan kerja, sedangkan tindakan tidak aman yang mengalami kecelakaan kerja sebanyak 16 orang $(30,1 \%)$. Dalam penelitian ini terlihat bahwa kecelakaan kerja yang terjadi lebih banyak disebabkan oleh kondisi tidak aman.

Kondisi tidak aman dapat dilihat dari hasil penelitian di lapangan menunjukkan bahwa terdapat lingkungan tempat kerja terlalu bising, adanya kabelkabel yang berserakan ditempat kerja, tidak adanya APAR di tempat kerja, adanya alat yang beresiko kontak dengan listrik dan lantai berlubang. Lingkungan yang bising terjadi bersumber dari proses pekerjaan pengelasan. Kabel-kabel yang berserakan karena saat pekerja sudah istirahat bekerja kabel-kabel yang berserakan dibiarkan begitu saja dan tidak dibereskan sebelum istirahat. Tidak adanya APAR karena tidak disediakan oleh pemilik bengkel dan lantai berlubang merupakan efek dari proses kerja seperti terkena pukulan palu pada saat pekerja memukul besi dengan palu setelah di las. Maka dari itu, diharapkan kepada pemilik bengkel agar memfasilitasi lingkungan kerja dengan aman seperti menyediakan APAR di bengkel las ini karena bengkel las beresiko terjadinya bahaya kebakaran dan peledakan sehingga APAR sangat dibutuhkan serta diharapkan juga untuk pekerja agar membantu menjaga dan merawat lingkungan kerja sehingga terciptanya lingkungan kerja yang aman.

\section{Pengetahuan}

Hasil penelitian ini dapat dilihat bahwa lebih dari separuh $(56,3 \%)$ responden memiliki pengetahuan yang 
kurang baik. Hal ini dapat dilihat pada hasil penelitian diantaranya $81,3 \%$ responden tidak tahu tentang pengertian kecelakaan kerja, 71,9\% tidak mengetahui faktor penting yang dibutuhkan untuk mencegah kecelakaan kerja, 65,6\% tidak tahu tentang kegunaan APD, tidak tahu siapa yang wajib merawat APD yang telah disediakan oleh perusahaan dan tidak tahu bagaimana melindungi diri dari kecelakaan kerja.

Penelitian ini sejalan dengan penelitian yang dilakukan Aswar, dkk (2016) pada pekerja bengkel mobil menyatakan bahwa dari 49 responden, sebagian besar responden memiliki pengetahuan K3 kurang yaitu sebanyak 27 orang $(55,1 \%)$ sedangkan sebagian kecil responden memiliki pengetahuan $\mathrm{K} 3$ cukup yaitu sebanyak 22 orang (44,9\%).

Menurut Green dalam Notoatmodjo (2010), pengetahuan merupakan salah satu faktor penting dalam memotivasi seseorang dalam bertindak. Perilaku seseorang yang didasari pengetahuan akan lebih bersifat bertahan lama dari pada perilaku seseorang tanpa didasari pengetahuan.

Rendahnya pengetahuan seseorang berarti seseorang tersebut memiliki wawasan yang kurang, pemahaman yang kurang. Jika pengetahuan pekerja kurang baik maka pekerja tidak dapat bekerja dengan efektif sehingga dapat menimbulkan kecelakaan kerja. Hal ini dapat dilihat dari hasil penelitian dimana sebagian pekerja tidak mengetahui tentang pengertian kecelakaan kerja, tidak mengetahui faktor penting yang dibutuhkan untuk mencegah kecelakaan kerja, tidak mengetahui kegunaan APD, tidak mengetahui siapa yang wajib merawat APD yg sudah disediakan perusahaan serta tidak mengetahui cara melindungi diri dari kecelakaan kerja. Pengetahuan yang rendah terhadap pekerja dapat dilihat dari tingkat pendidikan pekerja yaitu masih ada yang tamatan SD dan SMP (37,5\%).

Diharapkan kepada pemilik bengkel untuk meningkatkan pengetahuan pekerja dengan memberikan pelatihan-pelatihan dan promosi K3 seperti penyuluhan tentang pentingnya APD saat bekerja menyediakan poster komunikasi bahaya ditempat kerja dan pekerja juga dapat menambah informasi serta wawasan melalui media massa.

\section{Analisis Bivariat}

\section{Hubungan Tindakan Tidak Aman dengan Kecelakaan Kerja}

Hasil penelitian menunjukkan bahwa pekerja yang memiliki tindakan tidak aman lebih banyak mengalami kecelakaan kerja $(76,5 \%)$ dibandingkan dengan responden yang memiliki tindakan aman (13,3\%). Berdasarkan hasil uji statistik diperoleh nilai $p$ value $=0,001$ berarti terdapat hubungan yang bermakna antara tindakan tidak aman dengan kecelakaan kerja pada pekerja di CV Cahaya Tiga.

Penelitian ini sesuai dengan penelitian yang dilakukan oleh Ismail et al (2012) dalam Septiana (2014) yang menunjukkan bahwa lebih dari $80 \%$ kecelakaan kerja yang terjadi disebabkan oleh unsafe actions atau tindakan tidak aman.

Dalam teori domino Heinrich meneliti 75.000 kasus kecelakaan kerja yang terdiri dari 12.000 kasus klaim ansuransi dan 63.000 kasus di industri, diperoleh bahwa terjadinya kecelakaan kerja disebabkan oleh tindakan tidak aman/berbahaya (unsafe actions) dari pekerja sebesar 73\%; 25\% disebabkan oleh kondisi yang tidak aman/berbahaya (unsafe conditions) yang terdiri dari $15 \%$ kesalahan pekerja dan $10 \%$ kondisi fisik dan mekanik; dan 2\% takdir/suratan tangan (acts of God). Dengan kata lain bahwa kecelakan kerja disebabkan oleh unsafe actions sebesar $88 \%$ (dapat dicegah), unsafe condition 10\% (dapat dicegah) dan $2 \%$ act of God (tidak dapat dicegah).

Berdasarkan hasil penelitian dilapangan menunjukkan bahwa kecelakaan kerja sering terjadi pada pekerja dikarenakan sebagian pekerja tidak menggunakan APD saat bekerja seperti tidak memakai sarung tangan, tidak memakai safety shoes saat bekerja, tidak memakai apron, tidak menggunakan kacamata pada saat sedang menggerinda besi dan bekerja sambil merokok. Pekerja tidak menggunakan sarung tangan 
dikarenakan pekerja merasa tidak nyaman menggunakan sarung tangan pada saat bekerja. Pekerja merasa genggaman alat las yang tidak tepat ketika menggunakan sarung tangan dan terasa licin. Tidak terbiasa memakai safety shoes karena terlalu berat dan tidak nyaman. Pekerja tidak menggunakan kacamata saat menggerinda dikarenakan pekerja merasa sudah terbiasa tidak memakai kacamata pada saat menggerinda. Selain itu, pekerja merasa bekerja sambil merokok efektif untuk menghilangkan bosan saat bekerja.

Fenomena di lapangan juga ditemukan adanya responden yang melakukan tindakan aman tetapi mengalami kecelakaan kerja. Hal ini kemungkinan disebabkan karena faktor keturunan atau sifat bawaan dari pekerja seperti sembrono, acuh tak acuh, pemarah dan tidak berkonsentrasi, suka melamun, tidak mau menerima pendapat orang lain, keras kepala dan mudah tersinggung.

Maka dari itu diharapkan pada pekerja agar selalu menggunakan APD pada saat melakukan pekerjaan pengelasan, selalu berhati-hati saat melakukan pekerjaan dan tidak bekerja sambil merokok. Perlu adanya pengawasan kepada pekerja agar pekerja terhindar dari tindakan yang tidak aman.

\section{Hubungan Kondisi Tidak Aman dengan Kecelakaan Kerja}

Berdasarkan tabel 6. dapat dilihat bahwa responden yang memiliki kondisi tidak aman lebih banyak mengalami kecelakaan kerja $(76,5 \%)$ dibandingkan dengan responden yang memiliki kondisi aman (13,3\%). Berdasarkan hasil uji statistik diperoleh nilai $p$ value $=0,001$ berarti terdapat hubungan yang bermakna antara kondisi tidak aman dengan kecelakaan kerja di CV. Cahaya Tiga Putri Kelurahan Sungai Sapih Kecamatan Kuranji Padang Tahun 2017.

Penelitian ini sejalan dengan penelitian yang dilakukan oleh Waruwu (2015) di Yogyakarta penyebab kecelakaan kerja di bengkel pengecatan mobil dimana di peroleh dari kondisi tidak aman 18 orang $(36,4 \%)$ di antaranya pernah mengalami kecelakaan kerja, sedangkan tindakan tidak aman yang mengalami kecelakaan kerja sebanyak 16 orang $(30,1 \%)$.

Kondisi tidak aman merupakan keadaan yang terdapat di lingkungan tempat kerja, dimana lingkungan tersebut dapat memicu terjadinya kecelakaan kerja. Menurut Heinrich Silaban (2014) secara umum penyebab langsung kecelakaan kerja terbagi atas dua golongan, yaitu unsafe action (faktor manusia) dan unsafe condition (faktor lingkungan). Unsafe action dapat disebabkan oleh faktor manusia itu sendiri seperti: ketidakseimbangan fisik tenaga kerja, kurang pendidikan, bekerja melebihi jam kerja, menjalankan pekerjaan tidak sesuai keahliannya dan mengangkut beban yang berlebihan, sedangkan kecelakaan yang disebabkan oleh keadaan yang tidak aman (unsafe condition) disebabkan karena tempat kerja yang tidak sesuai dengan aturan kesehatan dan keselamatan kerja yang telah ditentukan.

Berdasarkan hasil penelitian terhadap fenomena di lapangan bahwa lebih dari separuh responden memiliki kondisi tidak aman, seperti: lingkungan kerja terlalu bising, kabel-kabel berserakan, tidak tersedianya APAR di tempat kerja dan adanya lantai yang berlubang.

APAR sangat perlu disediakan di bengkel las dikarenakan adanya potensi risiko kebakaran dan peledakan. Pekerjaan pengelasan menimbulkan percikan api dan menggunakan tabung gas. Keduanya merupakan unsur pencetus terjadinya kebakaran.

Diharapkan pada pekerja agar dapat menata kabel yang berserakan agar terhidar dari korsleting. Perlu adanya perbaikan jalan yang berlubang agar terhindar dari kecelakaan. Pengusaha perlu melakukan perawatan terhadap alat las secara berkala dan perlu menyediakan APAR agar terhindar dari potensi bahaya kebakaran di tempat kerja.

\section{Hubungan Pegetahuan dengan Kecelakaan Kerja}

Berdasarkan tabel 7. dapat diketahui bahwa responden yang memiliki pengetahuan kurang baik lebih banyak mengalami kecelakaan kerja $(72,2 \%)$ 
dibandingkan dengan responden yang memiliki pengetahuan baik (14,3\%). Berdasarkan hasil uji statistik diperoleh nilai $p$ value $=0,004$ berarti terdapat hubungan yang bermakna antara pengetahuan dengan kecelakaan kerja di CV. Cahaya Tiga Putri.

Penelitian yang dilakukan oleh Siregar (2014) mengatakan bahwa responden yang memiliki pengetahuan rendah lebih banyak mengalami kecelakaan kerja ringan $(73,8 \%)$ dari pada responden yang memiliki pengetahuan tinggi (26,2\%). Hasil uji chi Square meunjukkan ada hubungan yang bermakna antara pengetahuan dengan kecelakaan ringan $(\mathrm{p}$ value $=0,000)$.

Menurut Green dalam Notoatmodjo (2010) pengetahuan merupakan salah satu faktor penting dalam memotivasi seseorang dalam bertindak. Perilaku seseorang yang didasari pengetahuan akan lebih bersifat bertahan lama dari pada perilaku seseorang tanpa didasari pengetahuan. Rendahnya pengetahuan seseorang berarti seseorang tersebut memiliki wawasan yang kurang, pemahaman yang kurang. Jika pengetahuan pekerja kurang baik maka pekerja tidak dapat bekerja dengan efektif sehingga dapat menimbulkan kecelakaan kerja.

Teori Bird dalam Silaban (2014) mengatakan bahwa salah satu penyebab kecelakaan kerja adalah basic causes yaitu penyebab dasar terjadinya kecelakaan kerja yang terdiri dari: pengetahuan yang kurang, motivasi kurang, keterampilan kutarang, problem/stres fisik atau mental dan kemampuan yang tidak cukup secara fisik dan mental.

Penelitian ini juga sejalan dengan penelitian yang di lakukan oleh Aswar, dkk (2016) yang mengatakan bahwa proporsi responden dengan pengetahuan K3 cukup sebagian besar responden mengalami kecelakaan kerja ringan 14 orang $(28,6 \%)$ dan tidak terdapat responden yang mengalami kecelakaan kerja berat, sedangkan proporsi responden dengan pengetahuan K3 kurang sebagian besar responden mengalami kecelakaan kerja berat 14 orang $(28,6 \%)$ dan sebagian kecil mengalami kecelakaan kerja ringan 3 orang $(6,1 \%)$. Hasil uji chi square didapatkan bahwa nilai $\mathrm{p}$ value $<\alpha$ sehingga terdapat hubungan antara pengetahuan K3 dengan kecelakaan kerja.

Tingkat pengetahuan yang kurang baik mampu mempengaruhi resiko terjadinya kecelakaan kerja. Hal ini dapat dilihat dari kenyataan yang ada dilapangan lebih dari separuh pekerja memiliki pengetahuan yang kurang baik, dimana masih ada pekerja yang tamatan SD dan SMP. Rendahnya tingkat pengetahuan pekerja maka akan berdampak pada kecelakaan kerja. Oleh karena itu, pemilik bengkel perlu meningkatkan pengetahuan K3 pada pekerja melalui pelatihanpelatihan serta memberikan promosi $\mathrm{K} 3$ pada pekerja sepeti memberikan penyuluhan tentang pentingnya APD saat bekerja, menyediakan poster komuikasi bahaya ditempat kerja.

\section{KESIMPULAN}

1. Kurang dari separuh $(46,9 \%)$ responden pernah mengalami kecelakaan kerja di CV. Cahaya Tiga Putri.

2. Lebih dari separuh $(53,1 \%)$ responden memiliki tindakan tidak aman di $\mathrm{CV}$. Cahaya Tiga Putri.

3. Lebih dari separuh $(53,1 \%)$ responden memiliki kondisi tidak aman di $\mathrm{CV}$. Cahaya Tiga Putri.

4. Lebih dari separuh $(56,3 \%)$ responden memiliki pengetahuan yang kurang baik di CV. Cahaya Tiga Putri.

5. Ada hubungan tindakan tidak aman dengan kecelakaan kerja di CV. Cahaya Tiga Putri.

6. Ada hubungan kondisi tidak aman dengan kecelakaan kerja di CV. Cahaya Tiga Putri.

7. Ada hubungan pengetahuan dengan kecelakaan kerja di CV. Cahaya Tiga Putri.

\section{SARAN}

1. Bagi Pemilik Bengkel

Diharapkan kepada pemilik bengkel agar dapat meningkatkan pengetahuan pekerja dengan memberikan pelatihan-pelatihan terhadap pekerja serta memberikan promosi kesehatan dan keselamatan kerja pada pekerja seperti penyuluhan tentang pentingnya APD saat 
bekerja dan menyediakan poster komunikasi bahaya di tempat kerja, menciptakan lingkungan kerja yang aman. Diharapkan kepada pemilik agar menyediakan APAR di bengkel tersebut, dan diharapkan agar dapat dibuat peraturan beserta sanksi yang tegas sehingga pekerja dapat bekerja dengan tindakan yang aman seperti selalu menggunakan APD saat melakukan pekerjaan pengelasan.

2. Bagi Pekerja Pengelasan

Diharapkan agar pekerja selalu menggunakan alat pelindung diri saat bekerja, membantu untuk menciptakan kondisi lingkungan kerja yang aman, diharapkan kepada pekerja untuk dapat meningkatkan pengetahuan dengan menambah informasi dan wawasan melalui media masa dan televisi.

3. Bagi Peneliti Selanjutnya

Diharapkan penelitian ini dapat dijadikan data pembanding bagi peneliti selanjutnya dan meneliti faktor lain yang berhubungan dengan kecelakaan kerja.

\section{DAFTAR PUSTAKA}

Aswar, E dkk. 2016. Faktor-Faktor yang Berhubungan dengan Kecelakaan Kerja pada Pekerja bengkel Mobil Kota Kendari. Jurnal Kesehatan Masyarakat. Hal : 5.

BPJS, Ketenagakerjaan. 2016. Jumlah Kecelakaan Kerja di Indonesia Masih Tinggi. [Online]. Dari : www.bpjsketenagakerjaan.go.id. $\quad$ [11 Desember 2016].

Kemenkes, RI. 2014. 1 Orang Pekerja Di Dunia Meninggal Setiap 15 Detik Karena Kecelakaan Kerja. [Online]. Dari : www.depkes.go.id. [22 Maret 2017].

Notoatmodjo, S. 2010. Ilmu Perilaku Kesehatan. Jakarta: Rienka Cipta, 2010.

Pratiwi, 2009. Tinjauan Faktor Perilaku Kerja Tidak Aman pada Pekerja Konstruksi Bagian Finishing PT. Waskita Karya Proyek Pembanguna Fasilitas dan Sarana Gelanggang Olahraga (GOR) Boker, Ciracas, Jakarta Timur 2009. Skripsi Fakultas Kesehatan Universitas Indonesia, Depok.

Septiana, D. A dan Mulyono. 2014.
Faktor-Faktor yang Mempengaruhi Unsafe Actions pada Pekerja Di Bagian Pengantongan Urea. Jurnal Kesehatan Masyarakat. Vol. 3, No. 1 Jan-Jun 2014 : 25-34.

Silaban, G. 2014. Keselamatan dan Kesehatan Kerja. Perc. CV. Prima Jaya. Medan.

Siregar, D. I. S. 2014. Faktor-Faktor yang Berhubungan dengan Kecelakaan Kerja Ringan Di PT AQUA Golden Mississippi Bekasi Tahun 2014. Skripsi Peminatan Kesehatan Dan Keselamatan Kerja Program Studi Kesehatan Masyarakat Fakultas Kedokteran dan Ilmu Kesehatan Universitas Negeri Syarif Hidayatullah Jakarta 2014.

Suma'mur, P.K. 2009. Higiene Perusahaan dan Kesehatan Kerja (HIPERKES). Jakarta: Sagung Seto.

Undang-Undang Nomor 1 Tahun 1970 Tentang Keselamatan Kerja.

Waruwu, 2015. Analisis Faktor Kesehatan dan Keselamatan dan Keselamatan Kerja Yang Signifikan Mempengaruhi Kecelakaan Kerja pada Proyek Pembangunan Apartement Student Castle. Yogyakarta. Jurnal Penelitian.

Wicaksono, Dimas T dan Tjipto Suwandi. 2014. Penyebab Terjadinya Substandard Practice Berdasarkan Teori Loss Causation Model Pada Pengelas Di PT Bangun Sarana Baja. Jurnal Kesehatan Masyarakat. 